\title{
Life in the fast lane: clinical and immuno-histological characteristics of tachycardia-induced cardiomyopathy - a retrospective study on 684 patients
}

\author{
Adnan Spahic ${ }^{1}$, Ting-Hui Cheng ${ }^{2}$, J. Christoph Geller ${ }^{3}$, Joerg Saenger ${ }^{1}$, and \\ Marc-Alexander Ohlow ${ }^{4}$ \\ ${ }^{1}$ Zentralklinik Bad Berka Gmbh \\ ${ }^{2}$ University Hospital Jena Clinic of Anesthesiology and Intensive Care Medicine \\ ${ }^{3}$ Zentralklinik Bad Berka \\ ${ }^{4}$ SRH Wald-Klinikum Gera
}

May 27, 2020

\begin{abstract}
Introduction: Tachycardia-induced cardiomyopathy (TCM) has been known for decades as a reversible form of non-ischemic cardiomyopathy. However, its mechanism and properties remain poorly understood. Methods: This retrospective study investigated endomyocardial biopsy samples from 18 patients with TCM and compared them with samples from 170 patients with dilated cardiomyopathy (DCM), and 496 patients with inflammatory cardiomyopathy (ICM). Results: 684 patients with recent-onset heart failure and reduced ejection fraction not caused by valvular or ischemic heart disease were analyzed. In the TCM group, $81 \%$ were male, mean age was $60 \pm 13$ years, and $94 \%$ had heart failure symptoms [?] 2 NYHA class. At baseline (BL), $78 \%$ had atrial fibrillation/flutter, and 11\% inappropriate sinus tachycardia, heart rate was higher compared to DCM and ICM patients $(122+-25$ versus $78+-21 ; \mathrm{p}<0.001)$. Mean ejection fraction at BL was lower compared to DCM and ICM $(27+-12 \%$ versus 39.0+-14.6\%; $\mathrm{p}=0.001)$, but improved significantly more during follow-up (FU) (20\% versus 6\%; $<0.001)$. At FU, heart rate and presence of sinus rhythm were similar in all groups. $69 \%$ of TCM patients underwent electrical cardioversion or ablation. Compared with DCM patients, TCM patients had a stronger myocardial expression of MHC class II and an equal amount of infiltration with T-cells/macrophages. Compared with ICM patients, the presence of T-cells/macrophages was significantly lower in TCM. The marker of apoptosis (caspase 3) was comparably elevated in TCM/ICM patients. Conclusion: TCM is characterized by immuno-histological changes comparable to DCM except for caspase 3 levels, which were similar to those in ICM.
\end{abstract}

\section{Introduction}

Long-standing tachycardia is a well-recognized cause of heart failure and left ventricular dysfunction and has led to the nomenclature, tachycardia-induced cardiomyopathy (TCM) [1]. TCM is generally partially or entirely reversible with adequate treatment of the underlying arrhythmia. Therapeutic options include drug therapy, cardioversion, or interventional/surgical ablation [1].

The diagnosis is usually made retrospectively after normalization of heart rate and recovery of left ventricular function (LVEF). The first documented case was described in 1913 in a young patient with atrial fibrillation and symptoms of heart failure [2]. However, the knowledge of the underlying pathophysiological mechanisms and histopathological changes is still limited.

Various animal studies have described the molecular pathophysiological features of TCM [3,4]. Induction of cardiomyopathy through rapid pacing in various animal models has provided insight into the changes 
that occur within the myocyte as well as the surrounding extracellular matrix [3,4]. In particular, sustained tachycardia causes changes in calcium homeostasis, matrix remodeling, and fibrosis, as well as neurohormonal activation parameters $[5,6,7]$. A study by Mueller et al. showed changes in cardiomyocyte and mitochondrial morphology accompanied by macrophage-dominated inflammation in TCM [8].

This study aimed to analyze endomyocardial biopsy samples from patients with TCM and compared them with samples from patients with dilated cardiomyopathy (DCM) and inflammatory cardiomyopathy (ICM).

\section{Methods}

A retrospective analysis was performed in consecutive patients treated at our institution with an LVEF [?] 50 $\%$ presenting with new-onset non-ischemic HF. The definition of TCM included: 1) heart rate on admission $>100$ beats/min and evidence of prolonged elevated heart rate; 2) recovery of LVEF after the restoration of sinus rhythm or rate control (> $5 \%$ absolute increase in LVEF [9]); and 3) exclusion of other causes of HF. The decision to perform EMB was based on clinical criteria and indications, as described previously $[10,11,12,13]$. Cardiomyopathies were defined according to classification criteria from the American Heart Association and the European Society of Cardiology $[12,13,14]$. Coronary artery disease as the cause of the reduced LVEF had to be excluded using coronary angiography before a patient was eligible for inclusion in the study. All patients were medically treated according to current guidelines, depending on the degree of HF symptoms and LVEF development [15].

LVEF was estimated by echocardiography using the modified Simpson's rule with images obtained from apical 4- and 2-chamber views. The study conformed to the principles outlined in the Declaration of Helsinki, and the local ethics committee approved the research protocol.

\section{Endomyocardial biopsy analysis.}

Biopsy specimens were taken with a dedicated bioptome (B-18110-S; $4.5 \mathrm{~mm}^{3}$, Mohnheim, Germany) advanced through various $7 \mathrm{~F}$ or $8 \mathrm{~F}$ coronary guiding catheters (JR4.0/AL1.0/JL4.0, Medtronic, Danvers, Mass). At least four biopsy specimens (median, $\mathrm{n}=5$ ) with a diameter of $1-3 \mathrm{~mm}$ were harvested under strictly sterile conditions. Two to three biopsy specimens were fixed in $4 \%$ buffered formaldehyde for hematoxylin and eosin, Masson's trichrome, and Giemsa staining and performance of immunohistology. Another two to three cardiac tissue samples were quick-frozen or fixed in RNAlater (Ambion Inc, Foster City, Calif) for PCR detection of viral genomes without loss of sensitivity [16]. Biopsy specimens were investigated within 24 hours. Immunohistological staining and detection of viral genomes were performed as previously described $[16,17]$.

\section{Statistical analysis}

Continuous variables are reported as mean value \pm standard deviation or median and interquartile ranges $\left(25^{\text {th }}-75^{\text {th }}\right.$ percentiles $)$ if appropriate. The normality of distribution was tested with the D'Agostino-Pearson omnibus normality test. Categorical variables are presented as absolute (n) and relative (\%) frequencies. The one-way ANOVA for multiple comparisons or the Kruskal-Wallis tests were used depending on the presence or absence of normal distribution of continuous variables. The Fisher-exact test was used for categorical variables. The paired T-test was used to compare baseline and follow-up continuous variables. A probability value of $<0.05$ was considered to be statistically significant. Statistical analysis was performed using the GraphPad Prism version 6.02 for Windows (GraphPad Software, La Jolla, California, USA).

Results We studied a cohort of 684 consecutive patients with recent-onset heart failure (HF) and reduced LVEF [?] $50 \%$ not caused by valvular or ischemic heart disease. In total, 18 patients retrospectively fulfilled criteria for TCM. The clinical characteristics of these patients were compared with 496 patients with inflammatory cardiomyopathy (ICM) and with 170 patients with dilated cardiomyopathy (DCM).

\section{Baseline characteristics}

In the TCM group, $83.3 \%$ of patients were men; the mean age of the study population was $57+-13.0$ years. Of these patients, $94.4 \%$ had HF symptoms of New York Heart Association (NYHA) functional class [?] 
II, being borderline significant compared to DCM and ICM patients (Table 1). The prevalence of fever was higher in the ICM group. Patients with TCM presented with a mean heart rate of $122+-25$ beats $/ \mathrm{min}$. At baseline, $72.2 \%$ of patients had atrial fibrillation or typical atrial flutter, the remaining patients presented with inadequate sinus tachycardia, atypical AV-node reentry tachycardia, or frequent premature ventricular complexes each (Table 1).

The majority of TCM patients received rhythm control therapy. Of these, $44.4 \%$ underwent electrical cardioversion, and $38.9 \%$ also underwent ablation. Heart rate at follow-up was similar in all groups, a finding indicating sufficient efficacy of antiarrhythmic therapy in patients with TCM (Table 1). On admission, patients with TCM had LV end-diastolic diameter similar to those of patients with DCM; however, LVEF at baseline was significantly lower in the TCM group (Table 2). As expected, the improvement of LVEF was significantly greater in patients with TCM compared with patients with ICM or DCM (Figure 1).

Table 1 : Baseline characteristics

Abbreviations: CCS: Canadian Cardiovascular Society; COPD: Chronic obstructive pulmonary disease; DCM: dilated cardiomyopathy; ICM: inflammatory cardiomyopathy; IQR: interquartile range; LVEDD: left ventricular end-diastolic diameter; NYHA: New York Heart Association; PVC: premature ventricular contraction; SD: standard deviation; SVT: supraventricular tachycardia; TCM: tachycardia-induced cardiomyopathy; VT: ventricular tachycardia. The numbers highlighted in boldface indicate statistically significant differences between groups.

Table 2: Biomarkers and echocardiographic characteristics.

Abbreviations: CK-MB: creatinine kinase; FU: follow-up; IQR: interquartile range; LA: left atrium; LVEDD: left ventricular end-diastolic diameter; LVEF: left ventricular ejection fraction; NT-BNP: brain natriuretic peptide; RV: right ventricle. The numbers highlighted in boldface indicate statistically significant differences between groups.

* $\mathrm{p}<0.001$ Baseline versus follow up

Figure 1 : Absolute LVEF changes during FU

TCM: tachycardia-induced cardiomyopathy; ICM: inflammatory cardiomyopathy; DCM: dilated cardiomyopathy; ${ }^{* * *}$ : p-value $<0.001$ compared to TCM

\section{Endomyocardial characteristics}

The presence of viral genomes in the TCM group was comparable to that of the DCM group, as was the presence of biomarkers of myocardial damage in the groups.

\section{Histological findings}

We compared histological findings in patients with TCM with findings in patients who had ICM or DCM. We found distinct differences in the presence of $\mathrm{T}$ cells, which were strongly associated with ICM $(0.2$ cells in high power field (HPF) in TCM vs. 1.1 cells in HPF in ICM vs. 0.27 cells in HPF in DCM; overall p $<0.0001$ ) (Figure 2A). The presence of CD 68 positive macrophages was not significantly more frequent in patients with TCM compared with DCM, but less frequent compared with patients with ICM ( 0.45 cells in HPF in TCM vs. 0.47 cells in HPF in DCM vs. 1.1 cells in HPF in ICM; overall p < 0.0001) (Figure 2B).

Figure 2: Comparison of Biopsies.

(A) $\mathrm{CD}^{+} \mathrm{T}$ cells and (B) $\mathrm{CD}^{+} 8^{+}$macrophages as well as (C) immunohistological score of myocardial fibrosis (trichrome staining), and (D) anti-cleaved caspase 3 are compared in myocardial biopsy samples from patients with tachycardia-induced cardiomyopathy (TCM), inflammatory cardiomyopathy (ICM), and dilated cardiomyopathy (DCM).

***: p-value $<0.001$ compared to TCM; ns: not significant compared to TCM 
In patients with TCM, MHC-II (anti-major histocompatibility complex class II) expression was similar to that in patients with ICM and significantly enhanced compared with DCM (38.9\% in TCM vs. $54.4 \%$ in ICM vs. $4.1 \%$ in DCM; overall $\mathrm{p}<0.0001$ ) (Figure 3 ).

Figure 3: MHC-II (anti-major histocompatibility complex class II) expression

TCM: tachycardia-induced cardiomyopathy; ICM: inflammatory cardiomyopathy; DCM: dilated cardiomyopathy; ${ }^{* * *}$ : p-value $<0.001$ compared to TCM

Patients with TCM had a moderately increased degree of fibrosis which was slightly higher in patients with DCM and ICM (fibrosis score [0 to 4]: 1.6 in TCM vs. 2.1 in ICM vs. 1.9 in DCM; severe fibrosis: $6.7 \%$ in TCM vs. $8.9 \%$ in ICM vs. $17.6 \%$ in DCM; overall $\mathrm{p}=0.45$ ) (Figure $2 \mathrm{C}$ ).

Apoptosis and cell death are essential issues in HF. The presence of cleaved caspase 3, a specific indicator for apoptosis, was lowest in the DCM (48\% cells in HPF in TCM vs. $50 \%$ cells in HPF in ICM vs. $42 \%$ cells in HPF in DCM; overall $\mathrm{p}<0.0001$ ). Notably, despite the excellent recovery potential of TCM, the marker of apoptosis in patients with TCM was elevated o a similar degree compared to those with ICM (Figure 2D).

\section{Histological findings in sinus rhythm and atrial fibrillation}

In order to further evaluate the impact of atrial fibrillation or tachycardia itself on endomyocardial biopsy findings, we compared patients in atrial fibrillation $(\mathrm{n}=112)$ on admission and those in sinus rhythm $(\mathrm{n}=$ 553 ), irrespective of their admission heart rate. In this comparison, we were not able to demonstrate any significant difference between patients in sinus rhythm and those in atrial fibrillation with respect to CD 3 positive cells $(0.84+-0.86$ versus $0.82+-0.76$ cells in HPF; $\mathrm{p}=0.88)$, CD 68 positive cells $(0.93+-0.72$ versus $0.97+-0.75$ cells in HPF; $\mathrm{p}=0.58)$, MHC II ( $55.7 \%$ versus $60.4 \%$ positive biopsies; $\mathrm{p}=0.75)$, fibrosis score $(2.0+-1.2$ versus $2.2+-1.2 ; \mathrm{p}=0.14)$, and cleaved caspase $3(46+-16 \%$ versus $45+-16 \%$; $\mathrm{p}=0.46)-$ Figure 4 .

Figure 4:Immunohistochemical findings in patients with sinus rhythm versus atrial fibrillation

(A) $\mathrm{CD}^{+} \mathrm{T}$ cells and $\mathrm{CD} 68^{+}$macrophages, (B) immunohistological score of myocardial fibrosis (trichrome staining), (C) MHC-II (anti-major histocompatibility complex class II) expression, and (D) anti-cleaved caspase 3 are compared in myocardial biopsy samples from patients with tachycardia-induced cardiomyopathy (TCM), inflammatory cardiomyopathy (ICM), and dilated cardiomyopathy (DCM).

ns: not significant compared to TCM

\section{Recovery of LVEF in patients with tachycardia-induced cardiomyopathy}

The absolute LVEF improvement of the total TCM cohort after a median of six months of FU was $21 \%$ (Table 1). We arbitrarily defined a group of TCM patients with good LVEF recovery (mean absolute LVEF improvement $>21 \%$ ) and compared it to the remaining TCM patients with an absolute LVEF improvement of [?] $21 \%$. The echocardiographic findings at baseline in the group with LVEF recovery $>21 \%$ were significantly worse compared to the group with LVEF recovery of [?] $21 \%$ - Table 3 . Otherwise, we were not able to demonstrate any significant differences between the two groups for baseline characteristics, clinical presentation, rhythm at FU, and immunohistochemical findings.

Table 3 : Characteristics of TCM patients with improved LVEF during follow-up

Abbreviations: $\mathrm{BL}=$ baseline; $\mathrm{FU}=$ follow up; IQR: interquartile range; LA: left atrium; LVEDD: left ventricular end-diastolic diameter; LVEF: left ventricular ejection fraction; NT-BNP: N-terminal brain natriuretic peptide; RV: right ventricle. The numbers highlighted in boldface indicate statistically significant differences between groups.

$* \mathrm{p}<0.001$ Baseline versus follow up

\section{Discussion}


Our retrospective study was designed to elucidate EMB results in patients with TCM further.

\section{Definition and diagnosis}

Arrhythmia characteristics contributing to TCM include not only the heart rate but also the arrhythmia type, duration, irregularity, and persistence [18]. An arrhythmia that is insidious, persistent, and well-tolerated is more likely to result in TCM [18]. Lack of persistent tachycardia from autonomic influences and resultant slower rates during sleep are likely to be the reasons that TCM is rare with inappropriate sinus tachycardia and postural orthostatic tachycardia syndrome. However, the average heart rate can be $>100$ beats $/$ min. There is no specific heart rate cutoff at which TCM develops, it seems to be age-dependent, and a heart rate two-times faster than the normal heart rate can be considered as a threshold for TCM [19].

\section{Immunohistological findings}

Myocardial infiltration with large amounts of macrophages and T-cells is regularly observed in ICM [8] and was also present in ICM patients in our group. Patients fulfilling the criteria of TCM had a distinct pattern compared to ICM patients. The presence of macrophages and T-cells was significantly lower in the TCM group and more comparable to alterations seen in DCM patients. These findings are in some contrast to a study of EMB results in TCM patients, where the authors demonstrated a macrophage-dominated myocardial inflammation [8], which has been described in animal studies as well [20]. These differences to our results might be, at least in part, explained by the relatively short duration of tachycardia in our cohort, which was $25 \%$ shorter compared to the animal studies; Mueller and colleagues did not report the duration of symptoms [8]. However, the relationship between arrhythmia to cardiomyopathy and the development of symptoms is difficult to determine because an arrhythmia could exist for a long time before its recognition and before TCM develops [18]. A study of 24 patients with TCM and HF, the median time from onset of arrhythmia to cardiomyopathy, and the development of HF was 4.2 years [21]. Also, in animal rapid atrial pacing TCM-models, there is a compensatory phase whereby LV dilatation, extracellular matrix remodeling, and neurohumoral activation occurs, but severe LV dysfunction does not. This phase is followed by a phase in which LV dysfunction becomes manifest and associated with defects in excitation-contraction coupling and LV myocyte remodeling and dysfunction [18]. So, the time point of EMB during the disease course will most probably have a significant impact on the results of the immunohistochemical analysis.

\section{Chicken or egg in tachycardia-induced cardiomyopathy}

It is intriguing to speculate in clinical settings whether atrial fibrillation itself, the resulting tachycardia (of any reason), or the combination of both leads to severely reduced left ventricular ejection fraction. A study demonstrated impaired myocardial energetics resulting in subtle left ventricular dysfunction despite successful catheter ablation in patients with "lone" atrial fibrillation [22]. Moreover, although the majority of TCM patients usually have a substantial improvement in mean ejection fraction, not all of them have a normalized LVEF at FU. Also, in our study, there was a group of TCM patients with excellent recovery (mean absolute LVEF improvement $34+-6.1 \%$ ) and almost normalization of LVEF to a mean of $52 \%$, but $56 \%$ of our TCM patients had significantly less improvement of LVEF $(8.1+-11 \%)$ with a mean LVEF of $41 \%$ after six months. This raises the possibility that underlying cardiomyopathy may have been exacerbated by uncontrolled tachycardia. Even if the LVEF improves, it is unclear whether this means cure [18] as the recovery of LVEF may not imply normalization of LV structure and function [18]. Notably, we found a relevant amount of fibrosis in TCM and also elevated markers of cardiomyocyte apoptosis (cleaved caspase 3) comparable to ICM patients in our series. This was also demonstrated in a study with 19 TCM patients [8] and might contribute to incomplete LVEF recovery after a "point of no return" has been passed.

To further address the chicken and egg issue, we compared the endomyocardial biopsy results of patients with atrial fibrillation (AF) on admission and those in sinus rhythm irrespective of admission heart rate. We were not able to demonstrate any significant differences between the AF or sinus rhythm group, which is supported by similar results reported by Mueller et al. [8].

The potential role of human activated pluripotent stem cell cardiomyocytes (iPSC-KM), which mainly medi- 
ate the contractile dysfunction in persistent tachycardia, is currently investigated. The underlying functional electrophysiologic mechanisms will be assessed by measuring the action potential and ion-currents as well as by analyzing the cellular ion homeostasis [23]. Next-generation sequencing and gene-expression profiles will help to analyze the underlying targets of persistent tachycardia in the myocardium and the type of regulation [23]. This is especially important as defined subgroups, e.g., patients with homozygous deletion polymorphism in the angiotensin-converting enzyme gene, have a higher probability of developing TCM when faced with persistent tachycardia, suggesting a potential genetic link [18,24].

\section{Limitations}

The results of this study should be interpreted with some caution as it is based on retrospective observational data from a single academic center. Another limitation is the overall low number of patients with TCM. Although viral genomes were found in a few patients with TCM but with no signs of viral myocarditis, we cannot entirely exclude a pathological role (including atrial myocarditis) of the detected viruses in these patients.

\section{Conclusions}

The main results of our study are: (1) Compared with patients with DCM, patients with TCM demonstrated significantly stronger myocardial expression of major histocompatibility complex class II molecule and an equal amount of infiltration with CD3 ${ }^{+}$T-cells and CD68 ${ }^{+}$macrophages. (2) Compared with patients with inflammatory cardiomyopathy, the presence of T-cells and macrophages was significantly lower in TCM. (3) Myocardial fibrosis was detected to a lower degree in patients with TCM compared with DCM and ICM. (4) The marker of apoptosis (cleaved caspase 3) was comparably elevated in TCM and ICM patients and significantly lower in the DCM group. Finally, we were not able to demonstrate on an immunohistological level significant differences neither in TCM patients in sinus rhythm versus atrial fibrillation at baseline nor in TCM patients with LVEF improvement larger than the mean of the total cohort (21\%) compared to TCM patients with less LVEF improvement.

Further prospective studies are warranted for better characterization of patients with TCM by EMB, which could help identify patients with TCM.

Conflict of interest: none declared

\section{References}

1. Ellis ER, Josephson ME. Heart failure and tachycardia-induced cardiomyopathy, Curr Heart Fail Rep. 2013;10(4):296-306.

2. Gossage AM, Braxton Hicks JA. On auricular fibrillation. QJ Med 1913; 6(4): 435-440

3. Neumann T, Ravens U, Heusch G. Characterization of excitation-contraction coupling in conscious dogs with pacing-induced heart failure. Cardiovasc Res 1998;37:456-66.

4. Ravens U, Davia K, Davies CH, O'Gara P, Drake-Holland AJ, Hynd JW, Noble MI, Harding SE. Tachycardia-induced failure alters contractile properties of canine ventricular myocytes. Cardiovasc Res 1996;32:613-21.

5. Shinbane JS, Wood MA, Jensen DN, Ellenbogen KA, Fitzpatrick AP, Scheinman MM. Tachycardiainduced cardiomyopathy: a review of animal models and clinical studies. J Am Coll Cardiol 1997;29:709-15.

6. Zellner JL, Spinale FG, Eble DM, Hewett KW, Crawford FA Jr. Alterations in myocyte shape and basement membrane attachment with tachycardia-induced heart failure. Circ Res 1991; 69:590-600.

7. Kajstura J, Zhang X, Liu Y, Szoke E, Cheng W, Olivetti G, Hintze H, Anversa P. The cellular basis of pacing-induced dilated cardiomyopathy: myocyte cell loss and myocyte cellular reactive hypertrophy. Circulation 1995;92:2306-17. 
8. Mueller KAL, Heinzmann D, Klingel K, Fallier-Becker P, Kandolf R, Kilias A, Walker-Allgaier B, Borst O, Kumbrink J, Kirchner T, Langer H, Geisler T, Schreieck J, Gramlich M, Gawaz M, Seizer P. Histopathological and Immunological Characteristics of Tachycardia-Induced Cardiomyopathy. J Am Coll Cardiol. 2017;69(17):2160-72.

9. Zhang Y, Guallar E, Blasco-Colmenares E, Butcher B, Norgard S, Nauffal V, Marine JE, Eldadah Z, Dickfeld T, Ellenbogen KA, Tomaselli GF, Cheng A. Changes in follow-up left ventricular ejection fraction associated with outcomes in primary prevention implantable cardioverter-defibrillator and cardiac resynchronization therapy device recipients. J Am Coll Cardiol. 2015;66(5):524-31.

10. Dickstein K, Cohen-Solal A, Filippatos G, McMurray JJ, Ponikowski P, Poole-Wilson PA, Stromberg A, van Veldhuisen DJ, Atar D, Hoes AW, Keren A, Mebazaa A, Nieminen M, Priori SG, Swedberg K; ESC Committee for Practice Guidelines (CPG). ESC Guidelines for the diagnosis and treatment of acute and chronic heart failure 2008: the Task Force for the Diagnosis and Treatment of Acute and Chronic Heart Failure 2008 of the European Society of Cardiology. Developed in collaboration with the Heart Failure Association of the ESC (HFA) and endorsed by the European Society of Intensive Care Medicine (ESICM). Eur J Heart Fail 2008;29:2388-442.

11. Leone O, Veinot JP, Angelini A, Baandrup UT, Basso C, Berry G, Bruneval P, Burke M, Butany J, Calabrese F, d'Amati G, Edwards WD, Fallon JT, Fishbein MC, Gallagher PJ, Halushka MK, McManus B, Pucci A, Rodriguez ER, Saffitz JE, Sheppard MN, Steenbergen C, Stone JR, Tan C, Thiene G, van der Wal AC, Winters GL. 2011 consensus statement on endomyocardial biopsy from the Association for European Cardiovascular Pathology and the Society for Cardiovascular Pathology. Cardiovasc Pathol 2012;21:245-74

12. Caforio AL, Pankuweit S, Arbustini E, Basso C, Gimeno-Blanes J, Felix SB, Fu M, Helio T, Heymans S, Jahns R, Klingel K, Linhart A, Maisch B, McKenna W, Mogensen J, Pinto YM, Ristic A, Schultheiss HP, Seggewiss H, Tavazzi L, Thiene G, Yilmaz A, Charron P, Elliott PM.; European Society of Cardiology Working Group on Myocardial and Pericardial Diseases. Current state of knowledge on etiology, diagnosis, management, and therapy of myocarditis: a position statement of the European Society of Cardiology Working Group on Myocardial and Pericardial Diseases. Eur Heart J 2013;34:2636-48.

13. Cooper LT, Baughman KL, Feldman AM, Frustaci A, Jessup M, Kuhl U, Levine GN, Narula J, Starling RC, Towbin J, Virmani R. The role of endomyocardial biopsy in the management of cardiovascular disease: a scientific statement from the American Heart Association, the American College of Cardiology, and the European Society of Cardiology. Eur Heart J 2007;28:3076-93.

14. Maron BJ, Towbin JA, Thiene G, Antzelevitch C, Corrado D, Arnett D, Moss AJ, Seidman CE, Young JB; American Heart Association; Council on Clinical Cardiology, Heart Failure and Transplantation Committee; Quality of Care and Outcomes Research and Functional Genomics and Translational Biology Interdisciplinary Working Groups; Council on Epidemiology and Prevention Contemporary definitions and classification of the cardiomyopathies: an American Heart Association Scientific Statement from the Council on Clinical Cardiology, Heart Failure and Transplantation Committee; Quality of Care and Outcomes Research and Functional Genomics and Translational Biology Interdisciplinary Working Groups; and Council on Epidemiology and Prevention. Circulation 2006;113:1807-16.

15. Ponikowski P, Voors AA, Anker SD, Bueno H, Cleland JGF, Coats AJS, Falk V, Gonzalez-Juanatey JR, Harjola VP, Jankowska EA, Jessup M, Linde C, Nihoyannopoulos P, Parissis JT, Pieske B, Riley JP, Rosano GMC, Ruilope LM, Ruschitzka F, Rutten FH, van der Meer P 2016 ESC Guidelines for the diagnosis and treatment of acute and chronic heart failure: The Task Force for the diagnosis and treatment of acute and chronic heart failure of the European Society of Cardiology (ESC); Eur Heart J 2016;37(27):2129-2200.

16. Ohlow MA, Michel C, Chen TH, Schmidt A, Sanger J, Lauer B, Brunelli M. Predictors of long-term outcome in patients with biopsy-proven inflammatory cardiomyopathy. J Geriatr Cardiol 2018;15:363- 
17. Ohlow MA, Chen TH, Schmidt A, Sanger J, Lauer B. Clinical profile of patients with advanced age and inflammatory dilated cardiomyopathy on endomyocardial biopsy. J Geriat Cardiol 2015;12:60-612

18.

Gopinathannair R, Etheridge SP, Marchlinski FE, Spinale FG, Lakkireddy D, Olshansky B. ArrhythmiaInduced Cardiomyopathies: Mechanisms, Recognition, and Management. J Am Coll Cardiol. 2015;66(15):1714-28

Kim DY, Kim SH, Ryu KH. Tachycardia induced cardiomyopathy. Korean Circ J. 2019;49(9):808-817 Nakamura R, Egashira K, Machida Y, Hayashidani S, Takeya M, Utsumi H, Tsutsui H, Takeshita A. Probucol attenuates left ventricular dysfunction and remodeling in tachycardia-induced heart failure: roles of oxidative stress and inflammation. Circulation 2002;106:362-7. Nerheim P, Birger-Botkin S, Piracha L, Olshansky B. Heart failure and sudden death in patients with tachycardia-induced cardiomyopathy and recurrent tachycardia. Circulation 2004;110:247-52. Wijesurendra RS, Liu A, Eichhorn C, Ariga R, Levelt E, Clarke WT, Rodgers CT, Karamitsos TD, Bashir Y, Ginks M, Rajappan K, Betts T, Ferreira VM, Neubauer S, Casadei B. Lone atrial fibrillation is associated with impaired left ventricular energetics that persists despite successful catheter ablation. Circulation 2016;134:1068-81. Pabel S. Functional and molecular mechanisms in tachycardia-mediated cardiomyopathy. Deutsch Med Wschr 2019;144(15):suppl., page 46

\section{Tables}

Table 1 : Baseline characteristics

\begin{tabular}{|c|c|c|c|c|c|}
\hline $\begin{array}{l}\text { Clinical } \\
\text { characteristics }\end{array}$ & $\begin{array}{l}\text { All patients (n } \\
=684)(100 \%)\end{array}$ & $\begin{array}{l}\text { TCM }(\mathrm{n}=18) \\
(2.6 \%)\end{array}$ & $\begin{array}{l}\text { ICM }(\mathrm{n}=496) \\
(72.7 \%)\end{array}$ & $\begin{array}{l}\text { DCM }(\mathrm{n}=170) \\
(24.9 \%)\end{array}$ & p-Value \\
\hline $\begin{array}{l}\text { Age [years]; } \\
\text { Mean } \pm \text { SD }\end{array}$ & $57 \pm 13$ & $60 \pm 13$ & $56 \pm 14$ & $58 \pm 14$ & 0.34 \\
\hline Sex [male] & $495(72.6 \%)$ & $15(83.3 \%)$ & $356(71.8 \%)$ & $126(75.9 \%)$ & 0.62 \\
\hline Comorbidities & Comorbidities & Comorbidities & Comorbidities & Comorbidities & Comorbidities \\
\hline $\begin{array}{l}\text { Coronary } \\
\text { artery disease }\end{array}$ & $28(4.1 \%)$ & $2(11.1 \%)$ & $21(4.2 \%)$ & $5(2.9 \%)$ & 0.58 \\
\hline $\begin{array}{l}\text { Prior coronary } \\
\text { artery bypass } \\
\text { grafting }\end{array}$ & $6(0.8 \%)$ & $0(0.0 \%)$ & $6(1.2 \%)$ & $0(0.0 \%)$ & 1.00 \\
\hline $\begin{array}{l}\text { Prior } \\
\text { percutaneous } \\
\text { coronary } \\
\text { intervention }\end{array}$ & $16(2.3 \%)$ & $2(11.1 \%)$ & $12(2.4 \%)$ & $2(1.2 \%)$ & 0.76 \\
\hline $\begin{array}{l}\text { History of } \\
\text { myocardial } \\
\text { infarction }\end{array}$ & $46(6.7 \%)$ & $0(0.0 \%)$ & $40(8.1 \%)$ & $6(3.5 \%)$ & 0.34 \\
\hline $\begin{array}{l}\text { Arterial } \\
\text { hypertension }\end{array}$ & $448(65.7 \%)$ & $13(72.2 \%)$ & $318(64.1 \%)$ & $119(70.0 \%)$ & 0.37 \\
\hline $\begin{array}{l}\text { Diabetes } \\
\text { mellitus }\end{array}$ & $179(26.2 \%)$ & $8(44.4 \%)$ & $130(26.2 \%)$ & $42(24.7 \%)$ & 0.25 \\
\hline Hyperlipidemia & $282(41.3 \%)$ & $7(38.9 \%)$ & $203(40.9 \%)$ & $73(42.9 \%)$ & 0.71 \\
\hline $\begin{array}{l}\text { Peripheral } \\
\text { artery disease }\end{array}$ & $18(2.6 \%)$ & $1(5.6 \%)$ & $11(2.2 \%)$ & $6(3.5 \%)$ & 1.00 \\
\hline
\end{tabular}




\begin{tabular}{|c|c|c|c|c|c|}
\hline $\begin{array}{l}\text { Prior transient } \\
\text { ischemic } \\
\text { attack or } \\
\text { stroke }\end{array}$ & $32(4.6 \%)$ & $3(16.7 \%)$ & $22(4.4 \%)$ & $8(4.7 \%)$ & 0.37 \\
\hline $\begin{array}{l}\text { Chronic } \\
\text { obstructive } \\
\text { pulmonary } \\
\text { disease }\end{array}$ & $79(11.6 \%)$ & $3(16.7 \%)$ & $58(11.7 \%)$ & $18(10.6 \%)$ & 1.00 \\
\hline $\begin{array}{l}\text { Clinical } \\
\text { presentation } \\
\text { Heart rhythm } \\
\text { on admission }\end{array}$ & $\begin{array}{l}\text { Clinical } \\
\text { presentation }\end{array}$ & $\begin{array}{l}\text { Clinical } \\
\text { presentation }\end{array}$ & $\begin{array}{l}\text { Clinical } \\
\text { presentation }\end{array}$ & $\begin{array}{l}\text { Clinical } \\
\text { presentation }\end{array}$ & $\begin{array}{l}\text { Clinical } \\
\text { presentation }\end{array}$ \\
\hline Sinus rhythm & $554(81.0 \%)$ & $2(11.1 \%)$ & $404(81.5 \%)$ & $148(87.0 \%)$ & $<0.0001$ \\
\hline $\mathrm{PVC}$ & $1(0.2 \%)$ & $1(5.6 \%)$ & $0(0.0 \%)$ & $0(0.0 \%)$ & \\
\hline Atrial fibrillation & $119(17.4 \%)$ & $13(72.2 \%)$ & $87(17.5 \%)$ & $19(11.2 \%)$ & \\
\hline Atrial flutter & $5(0.7 \%)$ & $1(5.6 \%)$ & $2(0.4 \%)$ & $2(1.2 \%)$ & \\
\hline $\mathrm{SVT}$ & $2(0.3 \%)$ & $1(5.6 \%)$ & $1(0.2 \%)$ & $0(0.0 \%)$ & \\
\hline VT & $3(0.4 \%)$ & $0(0.0 \%)$ & $2(0.4 \%)$ & $1(0.6 \%)$ & \\
\hline $\begin{array}{l}\text { Heart rate } \\
\text { [beats/min] }\end{array}$ & $78 \pm 21$ & $122 \pm 25$ & $78 \pm 21$ & $76 \pm 14$ & $<0.0001$ \\
\hline $\begin{array}{l}\text { Duration of } \\
\text { symptoms } \\
\text { [days]; Mean } \\
\pm \text { SD }\end{array}$ & $87 \pm 162$ & $21 \pm 17$ & $87 \pm 169$ & $88 \pm 157$ & 0.04 \\
\hline Fever & $110(16.1 \%)$ & $1(5.6 \%)$ & $89(17.9 \%)$ & $20(11.8 \%)$ & 0.03 \\
\hline $\begin{array}{l}\text { Acute } \\
\text { coronary } \\
\text { syndrome }\end{array}$ & $166(24.3 \%)$ & $4(22.2 \%)$ & $122(24.6 \%)$ & $40(23.5 \%)$ & 1.00 \\
\hline $\begin{array}{l}\text { CCS } \\
\text { functional } \\
\text { class [?] II }\end{array}$ & $297(43.6 \%)$ & $4(22.2 \%)$ & $224(45.2 \%)$ & $69(40.6 \%)$ & 0.19 \\
\hline $\begin{array}{l}\text { NYHA } \\
\text { functional } \\
\text { class [?] II }\end{array}$ & $480(70.4 \%)$ & $17(94.4 \%)$ & $351(70.8 \%)$ & $114(67.1 \%)$ & 0.05 \\
\hline Fatigue & $224(32.8 \%)$ & $6(33.3 \%)$ & $173(34.9 \%)$ & $47(27.6 \%)$ & 0.18 \\
\hline $\begin{array}{l}\text { Pulmonary } \\
\text { edema }\end{array}$ & $76(11.1 \%)$ & $2(11.1 \%)$ & $60(12.1 \%)$ & $15(8.8 \%)$ & 0.41 \\
\hline Syncope & $46(6.7 \%)$ & $2(11.1 \%)$ & $31(6.3 \%)$ & $13(7.6 \%)$ & 0.53 \\
\hline $\begin{array}{l}\text { Body-mass- } \\
\text { index }\left[\mathrm{kg} / \mathrm{m}^{2}\right] \\
\text { Mean } \pm \mathrm{SD} \\
\text { Blood pressure } \\
{[\mathrm{mmHg}]}\end{array}$ & $28 \pm 5.1$ & $27 \pm 3.4$ & $28.6 \pm 5.3$ & $28 \pm 4.9$ & 0.68 \\
\hline systolic & $134 \pm 22$ & $133 \pm 22$ & $133 \pm 21.8$ & $138 \pm 23$ & 0.02 \\
\hline diastolic & $80 \pm 12$ & $84 \pm 17$ & $80 \pm 11.4$ & $82 \pm 13$ & 0.15 \\
\hline mean & $97 \pm 14$ & $100 \pm 19$ & $96 \pm 13.5$ & $100 \pm 15$ & 0.004 \\
\hline $\begin{array}{l}\text { Peripheral } \\
\text { edema }\end{array}$ & $133(19.5 \%)$ & $6(33.3 \%)$ & $95(19.2 \%)$ & $33(19.4 \%)$ & 0.30 \\
\hline $\begin{array}{l}\text { Jugular venous } \\
\text { distension }\end{array}$ & $12(1.8 \%)$ & $0(0.0 \%)$ & $8(1.6 \%)$ & $4(2.4 \%)$ & 1.00 \\
\hline Rales & $86(12.6 \%)$ & $3(16.7 \%)$ & $59(12.1 \%)$ & $24(14.1 \%)$ & 1.00 \\
\hline
\end{tabular}




\begin{tabular}{|c|c|c|c|c|c|}
\hline $\begin{array}{l}\text { Heart } \\
\text { rhvthm }\end{array}$ & Heart & $\begin{array}{l}\text { Heart } \\
\text { rhythm }\end{array}$ & $\begin{array}{l}\text { Heart } \\
\text { rhythm }\end{array}$ & $\begin{array}{l}\text { Heart } \\
\text { rhvthm }\end{array}$ & $\begin{array}{l}\text { Heart } \\
\text { rhythm }\end{array}$ \\
\hline during & during & during & during & during & during \\
\hline follow up & follow up & follow up & follow up & follow up & follow up \\
\hline Sinus rhythm & $556(81.5 \%)$ & $15(83.3 \%)$ & $397(80.1 \%)$ & $146(85.9 \%)$ & 0.24 \\
\hline Atrial fibrillation & $118(17.3 \%)$ & $3(16.7 \%)$ & $91(18.3 \%)$ & $24(14.1 \%)$ & 0.30 \\
\hline $\begin{array}{l}\text { Heart rate } \\
\text { [beats/min] }\end{array}$ & $71.6 \pm 20.5$ & $72.5 \pm 9.2$ & $71.6 \pm 20.3$ & $68.3 \pm 21.2$ & 0.45 \\
\hline $\begin{array}{l}\text { Electrical } \\
\text { cardioversion }\end{array}$ & $80(11.7 \%)$ & $9(50.0 \%)$ & $52(10.5 \%)$ & $21(12.4 \%)$ & 0.0002 \\
\hline Ablation & $35(5.1 \%)$ & $7(38.9 \%)$ & $15(3.1 \%)$ & $14(8.2 \%)$ & 0.0002 \\
\hline
\end{tabular}

Abbreviations: CCS: Canadian Cardiovascular Society; COPD: Chronic obstructive pulmonary disease; DCM: dilated cardiomyopathy; ICM: inflammatory cardiomyopathy; IQR: interquartile range; LVEDD: left ventricular end-diastolic diameter; NYHA: New York Heart Association; PVC: premature ventricular contraction; SD: standard deviation; SVT: supraventricular tachycardia; TCM: tachycardia-induced cardiomyopathy; VT: ventricular tachycardia. The numbers highlighted in boldface indicate statistically significant differences between groups.

Table 2: Biomarkers and echocardiographic characteristics.

\begin{tabular}{|c|c|c|c|c|c|}
\hline Variable & $\begin{array}{l}\text { All patients (n } \\
=684)(100 \%)\end{array}$ & $\begin{array}{l}\text { TCM }(\mathrm{n}=18) \\
(2.6 \%)\end{array}$ & $\begin{array}{l}\text { ICM }(\mathrm{n}=496) \\
(72.7 \%)\end{array}$ & $\begin{array}{l}\text { DCM }(\mathrm{n}=170) \\
(24.9 \%)\end{array}$ & p-Value \\
\hline $\begin{array}{l}\text { Laboratory } \\
\text { on admission }\end{array}$ & $\begin{array}{l}\text { Laboratory } \\
\text { on admission }\end{array}$ & $\begin{array}{l}\text { Laboratory } \\
\text { on admission }\end{array}$ & $\begin{array}{l}\text { Laboratory } \\
\text { on admission }\end{array}$ & $\begin{array}{l}\text { Laboratory } \\
\text { on admission }\end{array}$ & $\begin{array}{l}\text { Laboratory } \\
\text { on admission }\end{array}$ \\
\hline $\begin{array}{l}\text { Potassium } \\
{[\mathrm{mmol} / \mathrm{l}]}\end{array}$ & $4.2 \pm 0.51$ & $4.2 \pm 0.75$ & $4.2 \pm 0.51$ & $4.3 \pm 0.55$ & 0.71 \\
\hline $\begin{array}{l}\text { Creatinine } \\
{[\mathrm{mg} / \mathrm{dl}]}\end{array}$ & $99 \pm 59$ & $113 \pm 39$ & $99 \pm 57$ & $96 \pm 34$ & 0.38 \\
\hline $\begin{array}{l}\text { C-reactive } \\
\text { protein } \\
{[\mathrm{mg} / \mathrm{dl}]}\end{array}$ & $13 \pm 28$ & $14 \pm 13$ & $13.2 \pm 27$ & $13.0 \pm 29$ & 0.96 \\
\hline $\begin{array}{l}\text { Creatinkinase } \\
{\left[\mathrm{x} 10^{3} \mathrm{U} / \mathrm{l}\right]}\end{array}$ & $4.4 \pm 9.2$ & $2.8 \pm 2.0$ & $4.6 \pm 9.6$ & $3.2 \pm 3.2$ & 0.48 \\
\hline $\begin{array}{l}\text { NT pro-BNP } \\
{[\mathrm{pg} / \mathrm{ml}] ;} \\
\text { Median (IQR) }\end{array}$ & $\begin{array}{l}2595 \\
(538-5672)\end{array}$ & $\begin{array}{l}2665 \\
(189-5141)\end{array}$ & $\begin{array}{l}2595 \\
(672-7042)\end{array}$ & $\begin{array}{l}2630 \\
(451-5131)\end{array}$ & 0.42 \\
\hline $\begin{array}{l}\text { Hemoglobin } \\
{[\mathrm{g} / \mathrm{dl}]}\end{array}$ & $8.9 \pm 1.1$ & $8.9 \pm 1.1$ & $8.9 \pm 1.1$ & $9.0 \pm 1.0$ & 0.76 \\
\hline $\begin{array}{l}\text { White blood } \\
\text { cell }\left[\mathrm{x} 10^{3} / \mu \mathrm{l}\right]\end{array}$ & $8.6 \pm 2.9$ & $11 \pm 2.4$ & $8.6 \pm 2.9$ & $8.6 \pm 3.0$ & 0.005 \\
\hline $\begin{array}{l}\text { Troponin } \\
{[\mathrm{ng} / \mathrm{ml}]}\end{array}$ & $2.7 \pm 9.4$ & $0.89 \pm 0.87$ & $2.9 \pm 9.4$ & $1.7 \pm 4.6$ & 0.15 \\
\hline \multicolumn{6}{|c|}{ EchocardiographyEchocardiographyEchocardiographyEchocardiographyEchocardiographyEchocardiography } \\
\hline at $\mathrm{BL}$ & at $\mathrm{BL}$ & at $\mathrm{BL}$ & at $\mathrm{BL}$ & at $\mathrm{BL}$ & at $\mathrm{BL}$ \\
\hline LVEF $[\%]$ & $38 \pm 14$ & $26 \pm 12$ & $39.0 \pm 14.6$ & $38.4 \pm 15$ & 0.004 \\
\hline $\begin{array}{l}\text { LA diameter } \\
{[\mathrm{mm}]}\end{array}$ & $41 \pm 7.6$ & $42 \pm 6.3$ & $42 \pm 22.4$ & $42 \pm 6.3$ & 0.84 \\
\hline
\end{tabular}




\begin{tabular}{|c|c|c|c|c|c|}
\hline LVEDD [mm] & $57 \pm 8.9$ & $58 \pm 9.9$ & $57 \pm 8.8$ & $56 \pm 8.9$ & 0.46 \\
\hline $\begin{array}{l}\text { RV-pressure } \\
{[\mathrm{mmHg}]}\end{array}$ & $30 \pm 11$ & $31 \pm 9.2$ & $29.5 \pm 10.6$ & $30.3 \pm 13$ & 0.66 \\
\hline \multicolumn{6}{|c|}{ EchocardiographyEchocardiographyEchocardiographyEchocardiographyEchocardiographyEchocardiography } \\
\hline at FU & at $\mathrm{FU}$ & at $\mathrm{FU}$ & at FU & at FU & at $\mathbf{F U}$ \\
\hline LVEF [\%] & $44.5 \pm 13$ & $47 \pm 14^{*}$ & $44 \pm 13$ & $45 \pm 13^{*}$ & 0.75 \\
\hline Absolute & $6 \pm 12$ & $21 \pm 13$ & $6 \pm 12$ & $7 \pm 14$ & 0.002 \\
\hline \multicolumn{6}{|l|}{$\begin{array}{l}\text { LVEF } \\
\text { improvement } \\
{[\%]}\end{array}$} \\
\hline LVEDD [mm] & $55.9 \pm 7.7$ & $53 \pm 6.5$ & $55 \pm 7.2$ & $56 \pm 8.7$ & 0.46 \\
\hline
\end{tabular}

Abbreviations: CK-MB: creatinine kinase; FU: follow-up; IQR: interquartile range; LA: left atrium; LVEDD: left ventricular end-diastolic diameter; LVEF: left ventricular ejection fraction; NT-BNP: brain natriuretic peptide; RV: right ventricle. The numbers highlighted in boldface indicate statistically significant differences between groups.

* $\mathrm{p}<0.001$ Baseline versus follow up

Table 3 : Characteristics of TCM patients with improved LVEF during follow-up

\begin{tabular}{llll}
\hline Variable & $\begin{array}{l}\text { Improved LVEF during FU } \\
\text { Yes }(\mathrm{n}=8)(44.4 \%)\end{array}$ & $\begin{array}{l}\text { Improved LVEF during FU } \\
\text { No }(\mathrm{n}=10)(55.6 \%)\end{array}$ & p-Value \\
Biomarkers on admission & Biomarkers on admission & Biomarkers on admission & Biomarkers on adm \\
C-reactive protein [mg/dl] & $15 \pm 15$ & $13 \pm 12$ & 0.76 \\
Creatinkinase [x10 $\mathrm{U} / \mathrm{l}]$ & $2.7 \pm 2.1$ & $3.0 \pm 2.1$ & 0.85 \\
NT pro-BNP [pg/ml]; Median & 5141 & 891 & 0.06 \\
Troponin I [ng/ml] & $0.06 \pm 0.04$ & $0.12 \pm 0.11$ & 0.28 \\
Echocardiography at BL & Echocardiography at BL & Echocardiography at BL & Echocardiography a \\
LVEF [\%] & $18 \pm 9.2$ & $33 \pm 9.9$ & $\mathbf{0 . 0 0 4}$ \\
LA diameter [mm] & $41 \pm 4.4$ & $42 \pm 7.9$ & 0.79 \\
LVEDD [mm] & $63 \pm 7.5$ & $54 \pm 9.2$ & $\mathbf{0 . 0 4}$ \\
RV-pressure [mmHg] & $37 \pm 8$ & $26 \pm 7.6$ & $\mathbf{0 . 0 3}$ \\
Echocardiography at FU & Echocardiography at FU & Echocardiography at FU & Echocardiography a \\
LVEF [\%] & $52 \pm 7.8^{*}$ & $41 \pm 12^{*}$ & $\mathbf{0 . 0 4}$ \\
Absolute EF improvement [\%] & $34 \pm 6.1$ & $8.1 \pm 11$ & $<\mathbf{0 . 0 0 0 1}$ \\
LVEDD [mm] & $51.3 \pm 3.0^{*}$ & $55 \pm 7.9$ & 0.30 \\
\hline
\end{tabular}

Abbreviations: $\mathrm{BL}=$ baseline; $\mathrm{FU}=$ follow up; LA: left atrium; LVEDD: left ventricular end-diastolic diameter; LVEF: left ventricular ejection fraction; NT-BNP: N-terminal brain natriuretic peptide; RV: right ventricle. The numbers highlighted in boldface indicate statistically significant differences between groups.

$* \mathrm{p}<0.001$ Baseline versus follow up

Figure legends

Figure 1 : Absolute LVEF changes during FU

Figure 2: Comparison of Biopsies

Figure 3: MHC-II (anti-major histocompatibility complex class II) expression

Figure 4: Immuno-histochemical findings in patients with sinus rhythm versus atrial fibrillation 

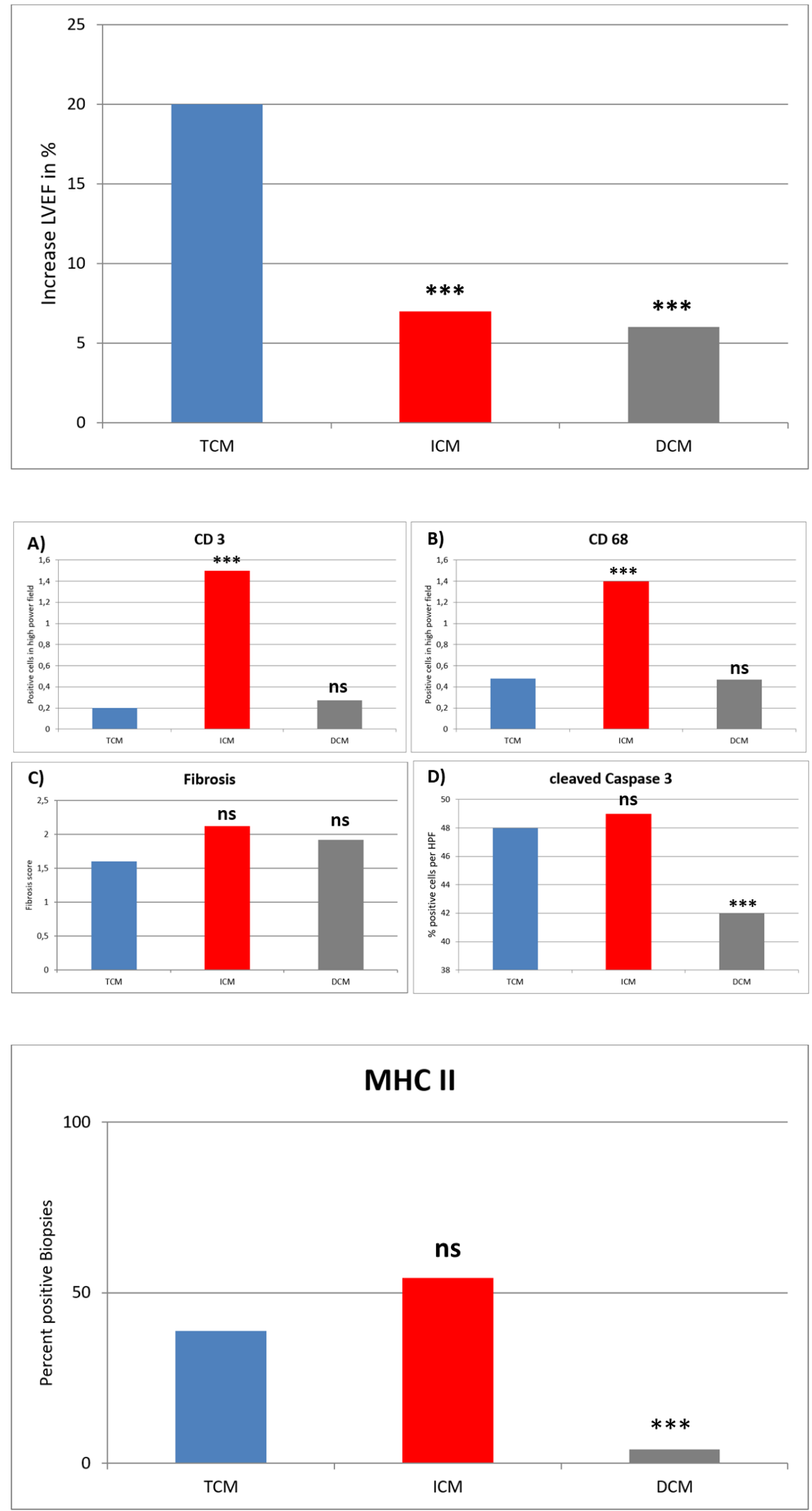


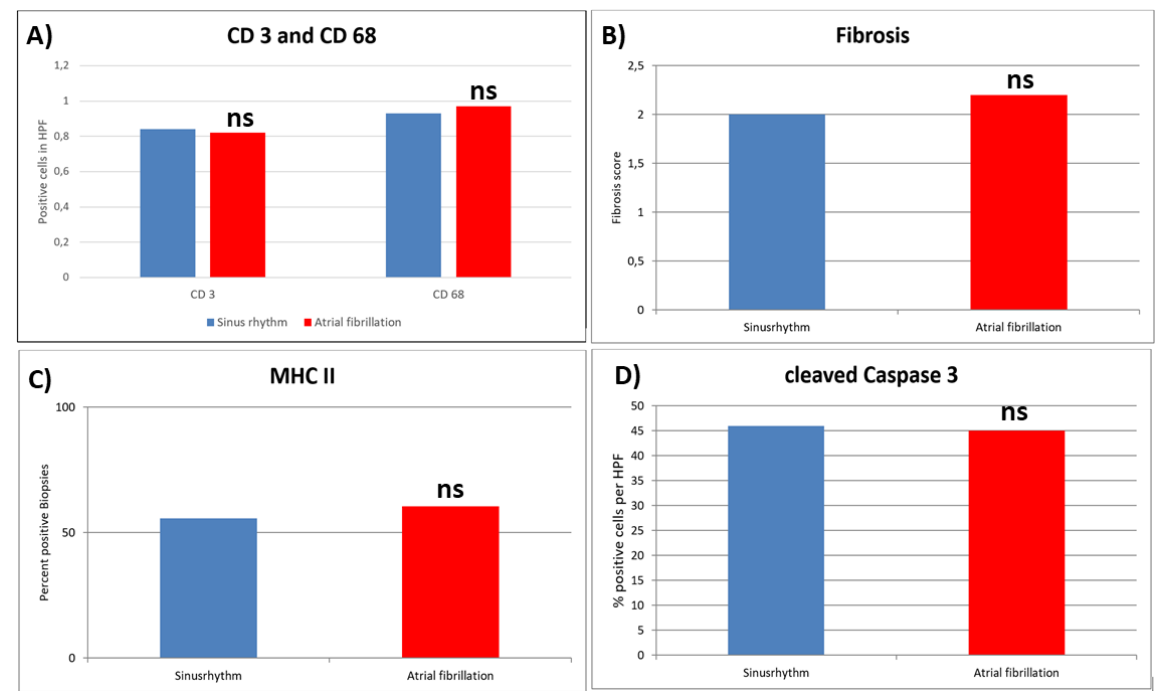

